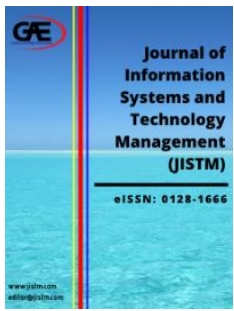

\author{
JOURNAL OF INFORMATION \\ SYSTEM AND TECHNOLOGY \\ MANAGEMENT (JISTM)

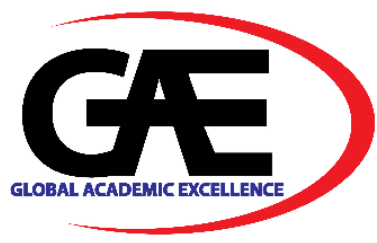

\title{
THE SMART WASTE MANAGEMENT SYSTEM OF SOLID WASTE MANAGEMENT IN UNIVERSITY CAMPUS
}

\author{
Danial Sim Wei Jie ${ }^{1 *}$, Haslina Arshad ${ }^{2}$, Siok Yee $\operatorname{Tan}^{3}$, Nur Fazidah Elias ${ }^{4}$ \\ 1 Institute of IR 4.0 (IIR4.0), Universiti Kebangsaan Malaysia, Selangor, Malaysia \\ Email: p107921@siswa.ukm.edu.my \\ 2 Institute of IR 4.0 (IIR4.0), Universiti Kebangsaan Malaysia, Selangor, Malaysia \\ Email: haslinarshad@ukm.edu.my \\ 3 Faculty of Information Science and Technology (FTSM), Universiti Kebangsaan Malaysia, Selangor, Malaysia \\ Email: esther@ukm.edu.my \\ 4 Faculty of Information Science and Technology (FTSM), Universiti Kebangsaan Malaysia, Selangor, Malaysia \\ Email: fazidah@ukm.edu.my \\ * Corresponding Author
}

\section{Article Info:}

Article history:

Received date: 10.06 .2021

Revised date: 15.07 .2021

Accepted date: 20.08.2021

Published date: 01.09.2021

\section{To cite this document:}

Sim, D., Arshad, H., Tan, S. Y., \& Elias, N. F. (2021). The Smart Waste Management System of Solid Waste Management in University Campus. Journal of Information System and Technology Management, 6 (22), 7187.

DOI: $10.35631 /$ JISTM.622007.

This work is licensed under $\mathrm{CC}$ BY 4.0

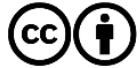

\begin{abstract}
:
It has been a challenge for Malaysia to handle solid waste management for more than a decade. The increase in population size has led to an increase in the waste amount contributed by Malaysians. Due to that, proper solid waste management is essential in protecting the environment. There are many ways to execute solid waste management but developing countries may find it challenging to find the best way to dispose of waste efficiently. The same phenomenon seems to happen on university campuses as well. This article aims to propose a smart waste management system for university campuses. Most of the related work concentrates on detecting bin levels, despite making it a full-fledged system that comprises several modules regardless of web or mobile platform. A prototype of a smart bin is proposed, and this paper discusses its architecture and functionality. A web-based user application is also proposed in this article. With these components, the system enables the user to obtain information on the bins around them and can help the management to manage solid waste more efficiently. With the help of the Internet of Things and Cloud services, the system can achieve a greener and more sustainable campus environment. The proposed system will also be enhanced further to increase the awareness among the university students to move forward to a greener campus.
\end{abstract}

Keywords:

Smart Bin, Waste Management, University Campus, Solid Waste Management 


\section{Introduction}

Solid waste management in Malaysia has been a challenge for more than a decade (Omran et al., 2007). It has been a complex and crucial task around the world (Zulkipli et al., 2018). Some developing countries are still struggling to decide the best options to treat and dispose of waste (Nadi et al., 2011). Its complexity increases due to rapid population, urbanisation process, and economic development (Zulkipli et al., 2018). The current method for waste disposal that is being practised in Malaysia is mainly by land disposal, potentially causing the sitting of landfills (Omran et al, 2007). The Department of Statistics Malaysia shows that the annual population growth rate was in the range of 0.4 to 2.4 per cent between the year 2010 to 2019 , as shown in Table 1.

Table 1: Total Population and Annual Population Growth Rate in Malaysia (2010-2019)

\begin{tabular}{ccc} 
Year & Total Population ('000) & Annual Population Growth Rate (\%) \\
\hline 2010 & $28,588.6$ & 1.8 \\
2011 & $29,062.0$ & 1.6 \\
2012 & $29,510.0$ & 1.5 \\
2013 & $30,213.7$ & 2.4 \\
2014 & $30,708.5$ & 1.6 \\
2015 & $31,186.1$ & 1.5 \\
2016 & $31,633.5$ & 1.4 \\
2017 & $32,022.6$ & 1.2 \\
2018 & $32,382.3$ & 1.1 \\
2019 & $32,523.0$ & 0.4 \\
\hline
\end{tabular}

Source: Department of Statistics Malaysia (2020)

Based on an obtained statistic from MHLG and World Bank, 1999 and 2003, we can infer that as the population size increases, the amount of waste generated daily also increases (Nadi et al., 2011). It is further validated years later. The Solid Waste Management and Public Cleansing Corporation (SWCorp) mentioned that Malaysians generated a whopping amount of 38,142 tons of waste every day in 2018. It is doubled based on the figure of 19,000 tonnes of waste daily back in 2005 (Fong, 2019). Improper waste management may cause a threat to our lives by creating an unhealthy environment.

Hence, a proper Smart Waste Management System (SWMS) is significant to create a smart, comfortable, and sustainable environment and cities (Harith et al., 2020). The introduction of the Industrial Revolution 4.0 (IR 4.0) concepts in 2011 lead to the evolvement of technologies such as the Internet of Things (IoT) and cloud computing (Alaloul et al., 2018; Kanase \& Kanse, 2018). The IoT has been useful in our daily lives as our daily devices are interconnected (Kanase \& Kanse, 2018). The SWMS can be made possible with the help of IoT and cloud services by transferring data via machine-to-machine (M2M) communications of sensory data to the cloud due to advancements in super-media (Zeb et al., 2019).

In this article, we will discuss the background related to solid waste management. And then, we will discuss some of the related works which other researchers have done. Next, we will 
present the proposed prototype of the SWMS in the following section. Lastly, some discussion on the acceptance and future work will be presented before we conclude the paper.

\section{Background}

This section will discuss the concept of solid waste management and the method of waste bin collection in Malaysia.

\section{The Concept of Solid Waste Management}

Before we discuss the concept of solid waste management, we need to understand the fundamental concepts first. What do we understand by waste, solid waste, as well as waste management in modern-day standards? Waste is defined as the useless by-product of human activities that contain the same substances available in the useful products (White et al., 1995; Basu, 2009). People would want to dispose of them even if payments are required for them (Dijkema et al., 2000).

Waste exists in many forms, and its characterisation can be expressed in different forms (Amasuomo \& Baird, 2016). Solid waste is one type of waste classification based on its physical states, other than liquid and gas (Tchobanoglous et al., 1993). Solid waste refers to a range of wastes produced from human activities in a solid or semi-solid form (Beranek, 1992; Vergara \& Tchobanoglous, 1992; Leblanc, 2020).

Unlike other wastes, solid wastes do not disappear easily (Tchobanoglous et al., 1993). It is still possible to find what humans throw today in the future (Amasuomo \& Baird, 2016). Therefore, proper planning and control are required to prevent the negative impact caused by the waste on the environment (Beranek, 1992). Waste management is a process in which wastes are gathered, transported, and processed before the disposal of any remaining residues (Demirbas, 2011).

A proper organisation of solid waste management has become an essential task to protect the environment (Ghiani et al., 2014). Its management techniques can vary from country to country, depending on several factors such as physical geography, demographics, and the level of economic development (Omran et al., 2007). Typical solid waste management involves large outdoor waste bins, waste pickup trucks, and scheduled pickup routines by the relevant authorities (Ab Majid et al., 2019). Such implementation is a common method practised by many developing countries today.

\section{Method on Waste Bin Collection in Malaysia}

The traditional method adopted in Malaysia is by emptying the waste bin at certain intervals, either daily or weekly. The responsible stakeholder oversees the process, which the related authorities have selected. Sometimes, the waste collection processes are not well scheduled for certain areas (Harith et al., 2020), and results in some drawbacks as described by the following:

- Some waste bins fill up much faster than the rate of emptying and causes them to become full easily before the next collection, especially in shared areas such as in flats. This situation poses hygiene risks to the public (Mohd Yusof et al, 2017; Zeb et al., 2019; Harith et al., 2020). 
- Some special days such as public holidays, weekends, and festivals tend to have a faster filling rate of the waste bins, resulting in shorter collection intervals (Zeb et al., 2019).

Based on the drawbacks discussed above, it is very important to ensure proper and efficient waste management, especially in common areas. The waste bins located in those areas tend to fill up quickly. The existing capacities in those waste bins may not be sufficient for areas shared with many people. Unsystematic and inefficient disposal waste management may cause the bins to be always full of garbage. Additionally, further littering from the residents will cause the garbage piles to scatter outside the bins (Mohd Yusof et al., 2017).

\section{Related Work}

This section will discuss some of the related works that other researchers have done. Some of the works included here may not be targeting university campuses. Nevertheless, each work has a different approach to address the waste management issues in different methodologies through their research and findings.

The research work in Harith et al. (2020) proposed a prototype on the IoT-based SWMS, which targets the University Malaya campus in the research. The prototype consists of sensor nodes, gateways, cloud platforms, and mobile and web applications. The smart bins in the system contain pieces of equipment such as sensors, microcontrollers, Global Positioning System (GPS), and Wi-Fi modules. The Application Programming Interface (API) implementation from Google Maps is for the route optimisation process and web servers for data handling and processing. The sensors communicate with the cloud service and reflect the corresponding data in the web application. The existence of the web application can help the management to monitor the current level and load of the bins located on the campus. There is also another web application which can help the contractor to locate the garbage trucks together with their respective capacity. The downside of this system is that it only covers basic information such as the current level and weight of the bin. In addition, the system cannot predict when a bin is due for collection as a way of prediction.

Based on (Ahmad et al., 2018), SmartBin is another solution to solid waste management. The Kemaman Municipal Council is currently using the SmartBin system in Terengganu, Malaysia ("Smartbin Waste Management," 2019). The system consists of the SmartBin App and SmartBin Web modules. The former is responsible for scanning all collected bins, while the latter manages, and monitors collected and uncollected bins (Ahmad et al., 2018). Each of the bins contains a QR code that links to the system. The deployment has reached 2700 bins in the system. The contractor in charge of the bins collection will scan the QR code in the bin before collection. The system will capture and keep the data for recording purposes ("Smartbin Waste Management," 2019). SmartBin mainly focuses on bin collection and not based on collection routes. It does not even detect the level of the bin.

Another solution includes the one from the research work as in (Pardini et al., 2020). The research work in (Pardini et al., 2020) uses a mobile application called the My Waste App on top of the web application. It comprises My Waste App as the application and My Waste Bin as the bin component. The research also proposes a middleware module that connects base systems such as IoT devices to each other and third-party applications (da Cruz et al., 2018a; da Cruz et al., 2018b). Although it is convenient to have mobile application access for instant 
Volume 6 Issue 22 (September 2021) PP. 71-87 DOI: 10.35631/JISTM.622007

checking, the functions proposed in this research are too simple. It does not cover as many functions as in Harith et al. (2020) since it only covers bin level checking.

The research work in A. A. et al., (2020) proposed another approach in monitoring bin levels by reflecting the data in terms of the bin levels in the form of a mobile application. Figure 1 shows some screenshots of the display for the bin levels in the mobile application. It only acts as an application to monitor the bin levels without any other functions. However, the research work manages to make the display differently instead of using only colour codes.

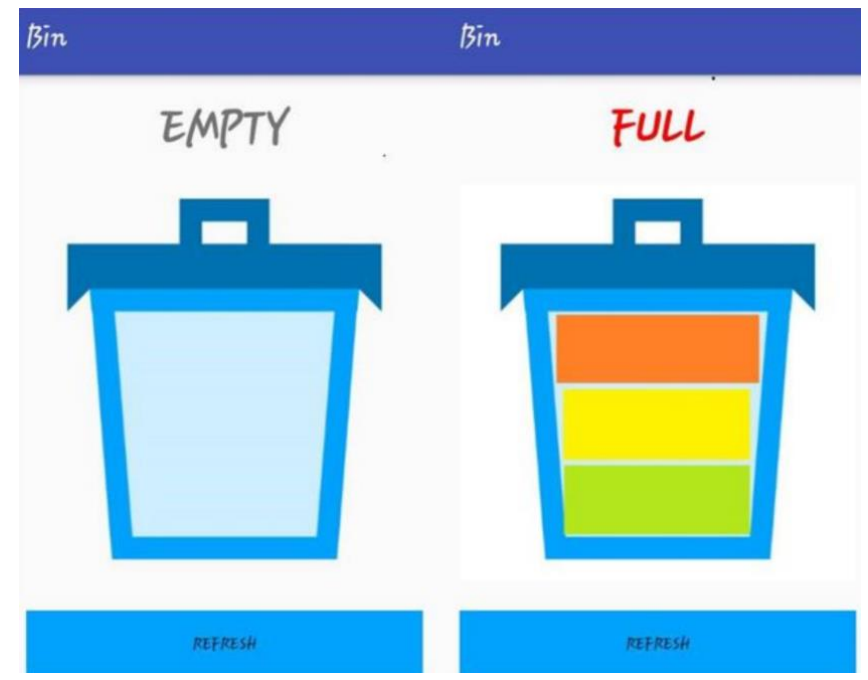

Figure 1: Displaying of The Bin Levels via The Mobile Application Source: A. A. et al. (2020)

Lastly, the research work in Mohd Yusof et al. (2017) proposed a different approach in monitoring bin levels. The usage of colour codes here is to display the levels of the bin in the respective levels. However, it does not involve any usage of gadgets to monitor the bin levels. The research work uses Low-Emission Diode (LED) lights to display the situation of the bin in each respective level, as shown in Figure 2. A warning SMS message will be sent as an alert to the related authorities for further actions.
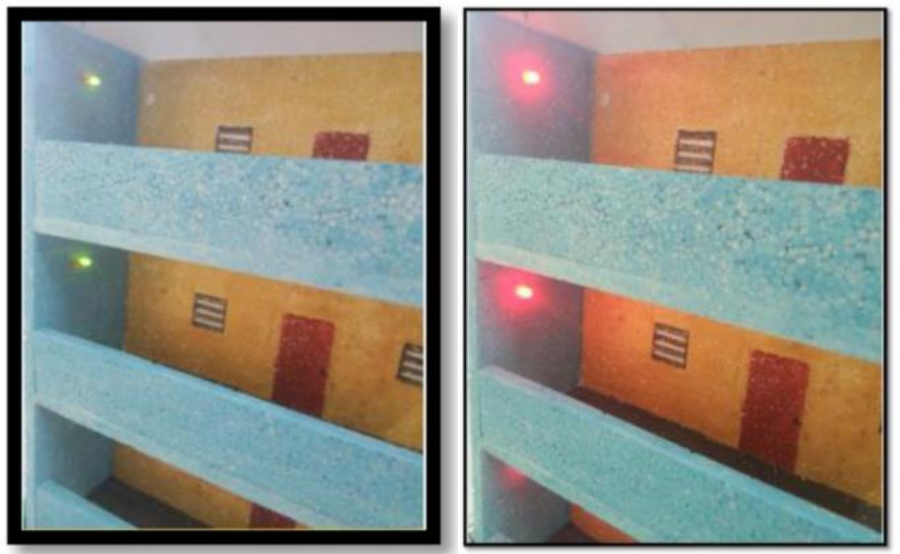

Figure 2: Displaying of the Bin Levels via LED Lights

Source: Mohd Yusof et al. (2017) 
Based on the discussion above, many research works have different ways to address and tackle waste management issues more smartly. Nevertheless, we need to ensure that we select an optimised method for this research.

\section{Methodology}

In this paper, we propose a SWMS to improve efficiency and effectiveness in solid waste management. The proposed system involves several modules and components. Figure 3 illustrates the modules and components involved in the proposed system through a hierarchy diagram.

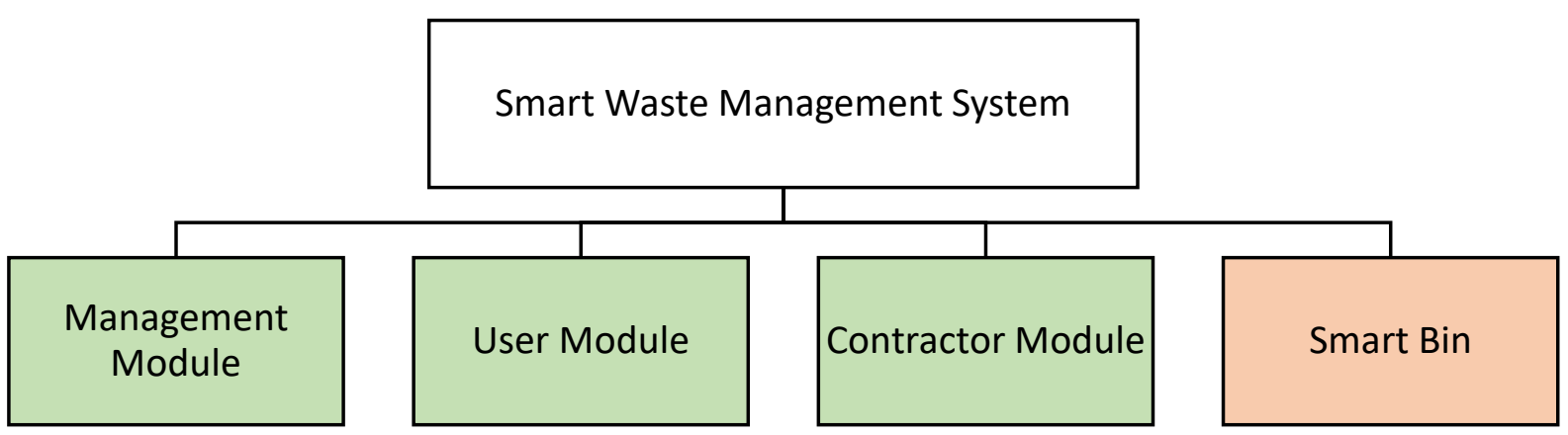

Figure 3: Module and Component of the Proposed System

Based on Figure 3, we can observe three types of end-users: the management, contractor, and normal user. Figure 4 shows the use-case diagram of the proposed system related to the endusers mentioned. The smart bin will be the only component involved in the proposed system. It will be responsible for sending all the information related to the bin through the sensors contained inside the smart bin. The system will send the information to the cloud, and the other modules can obtain the information via cloud services. The information will help perform functions proposed in the system effectively. The following is a brief overview about the proposed function in the system:

- Garbage bin maintenance (Location and status)

- Waste collection maintenance (Scheduling)

- Contractor maintenance (For management and contractor only)

- Collection route

- Complaint lodging

- Reporting and analysis (For management and contractor only) 


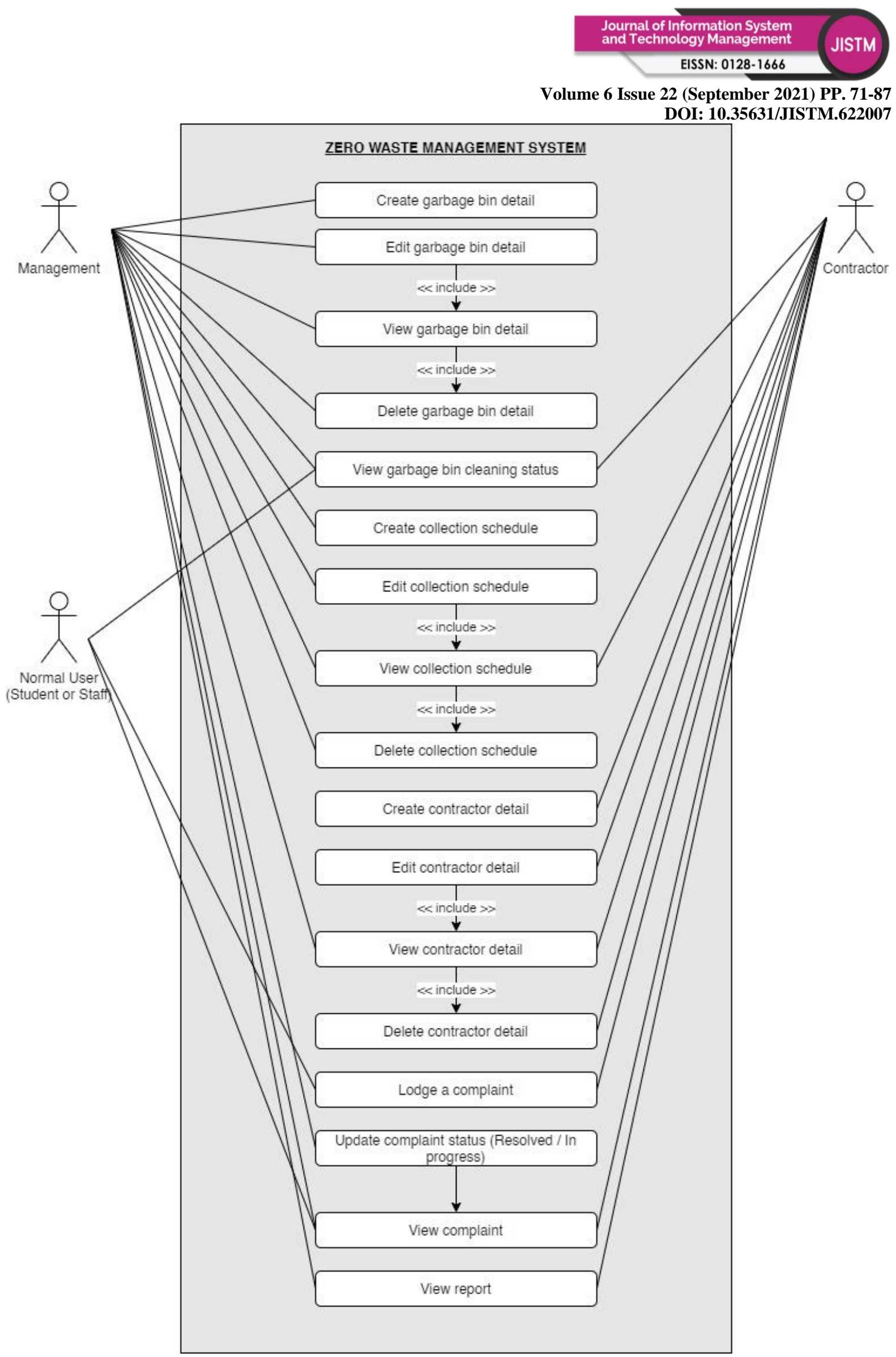

Figure 4: Use Case Diagram of the Proposed System 


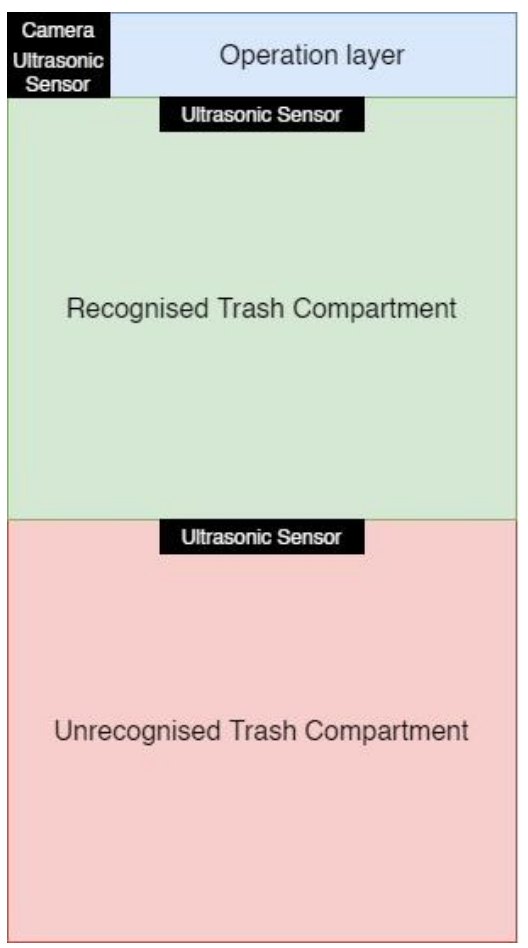

\section{Figure 5: Basic Architecture Diagram of the Smart Bin}

Figure 5 shows the basic architecture diagram of the smart bin. The smart bin comprises of three layers. The top layer is known as the operation layer, which will house the sensors, motors, GPS module, and transmitters responsible for the operation of the smart bin. The camera and ultrasonic sensor are installed in the same layer for trash detection purposes. Figure 6 illustrates further the operation layer in terms of design and layout. Underneath that layer there are two compartments where the trash is divided based on whether the trash is recognisable by the sensor or not. Ultrasonic sensors are installed in each of these layers to detect the level of the trash. The data is generated from the obtained result by the sensors. And then, it is sent to the cloud through the transmitter, which communicates with the cloud service.

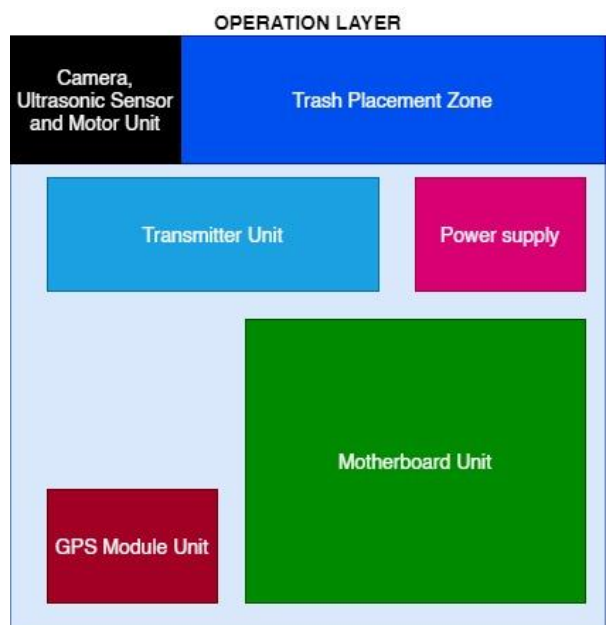

Figure 6: Design and Layout of the Operation Layer 
Volume 6 Issue 22 (September 2021) PP. 71-87 DOI: 10.35631/JISTM.622007

The transmitter unit will communicate with the cloud service to pass the data from the smart bin, such as the trash level inside the bin. The GPS module will determine the location of the bin and send the data to the cloud service for it to appear in the user application. The information is required so that the functions in the user application can run without hassle. The functions are illustrated through the module hierarchy diagram, as shown in Figure 7.

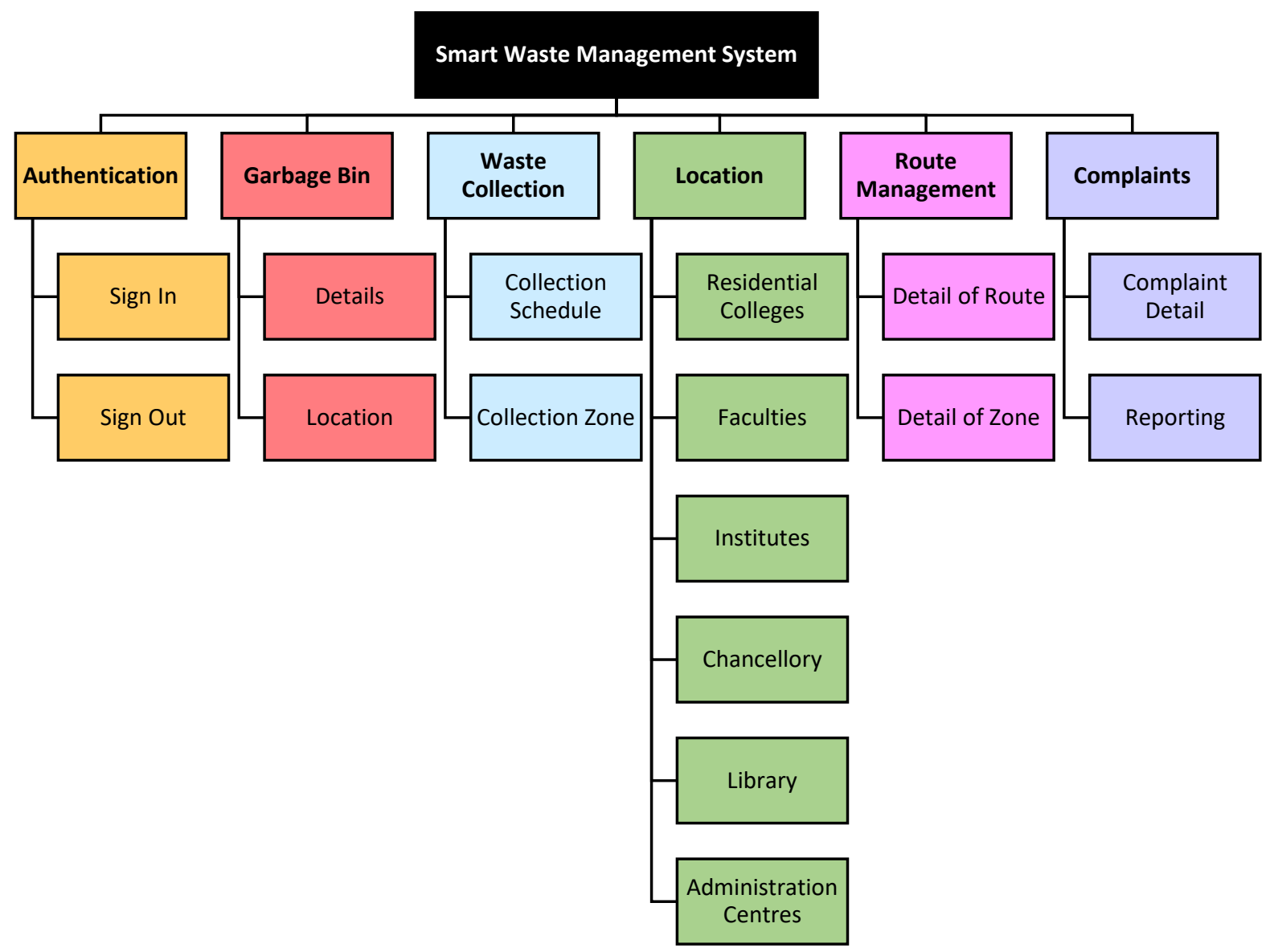

Figure 7: Module Hierarchy Diagram of the Proposed System

A simple web application has been developed at this stage. It acts as a prototype for the system in terms of the user module. Figures 8 until 12 illustrate some of the screenshots and their related explanations. The functions include:

- Authentication

- Announcement

- Reporting

- Location Maintenance

- Garbage Bin Maintenance

- Garbage Bin Location (display in maps form) 


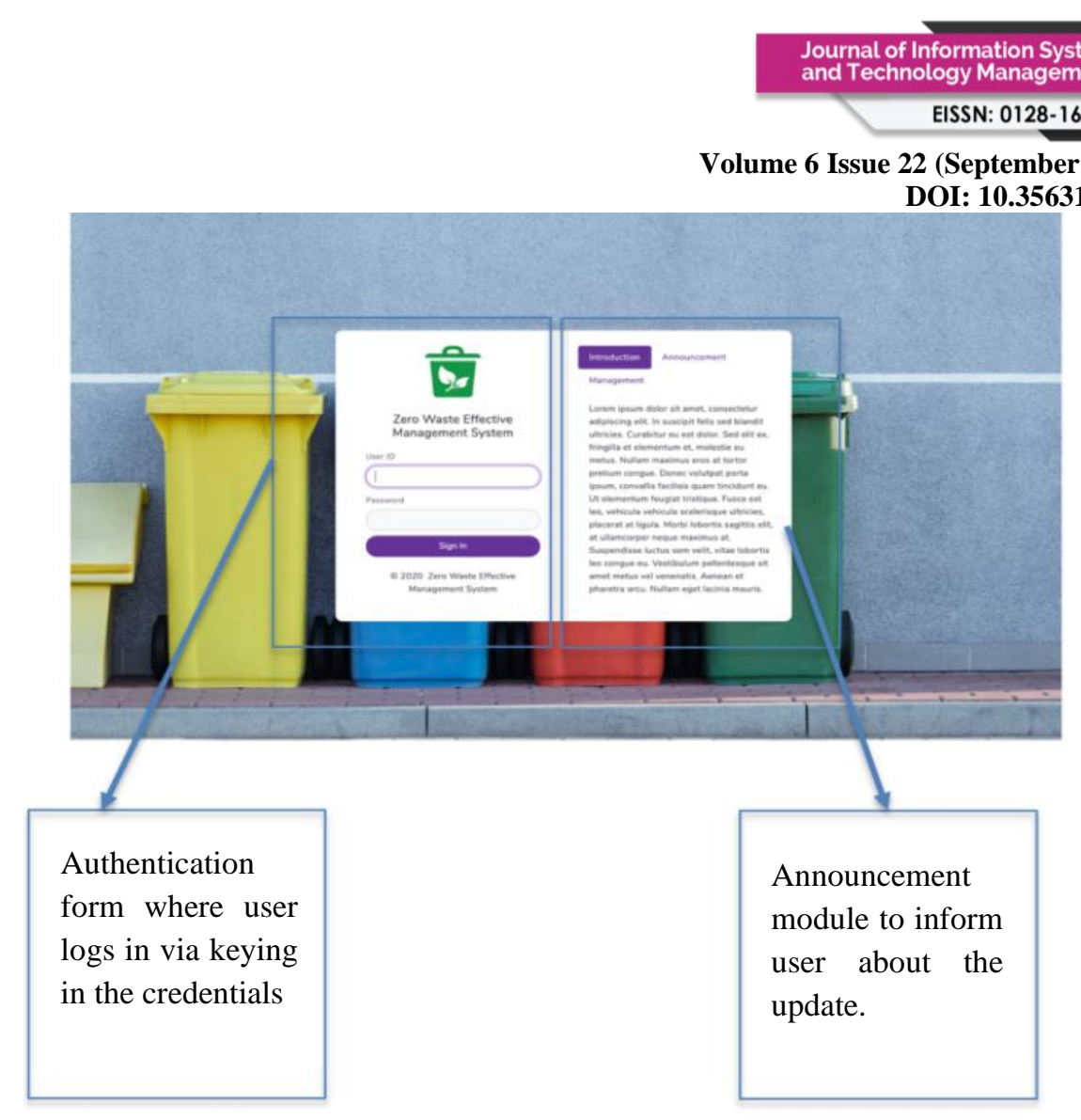

Figure 8: Authentication and Announcement

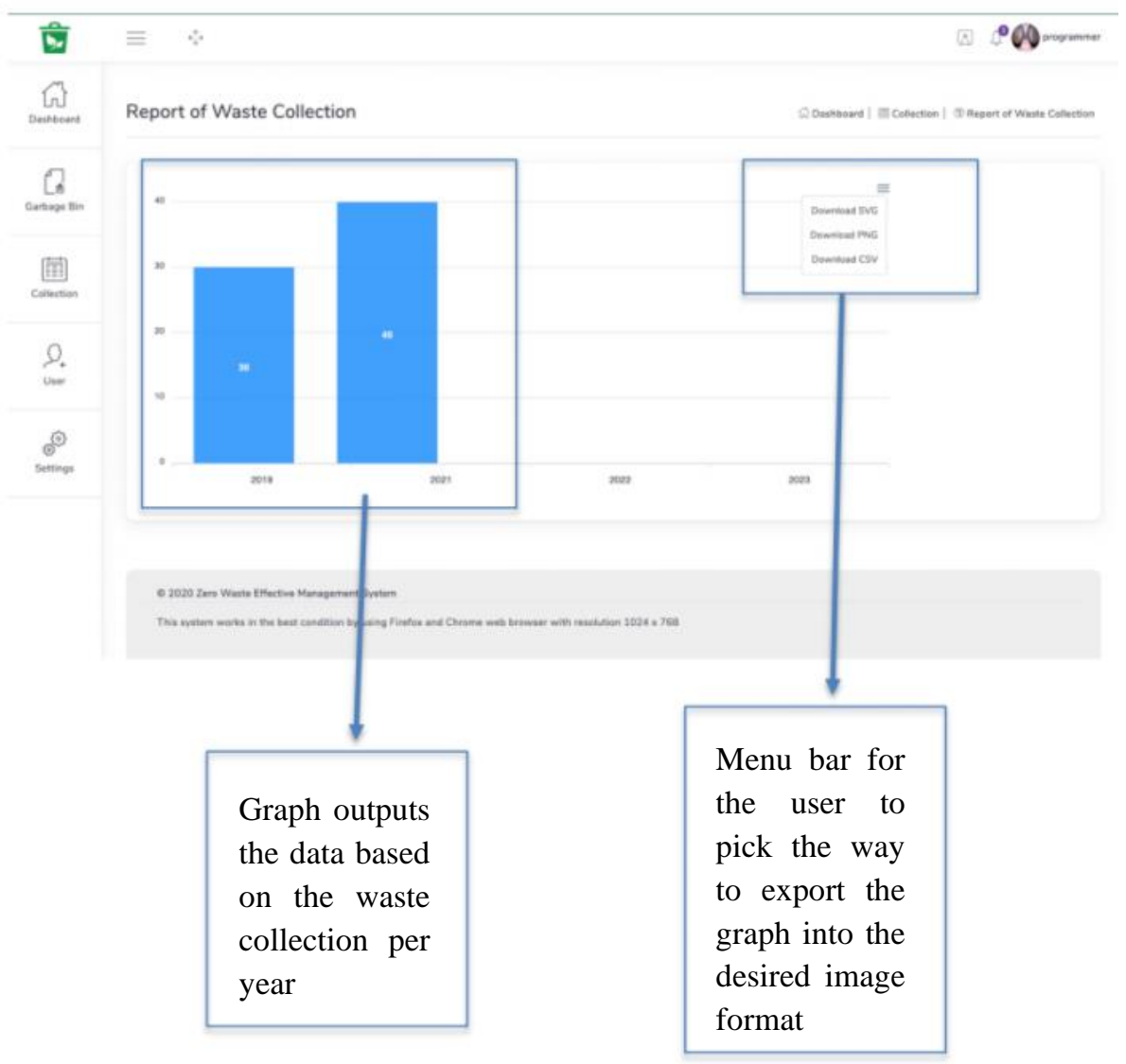

Figure 9: Reporting 


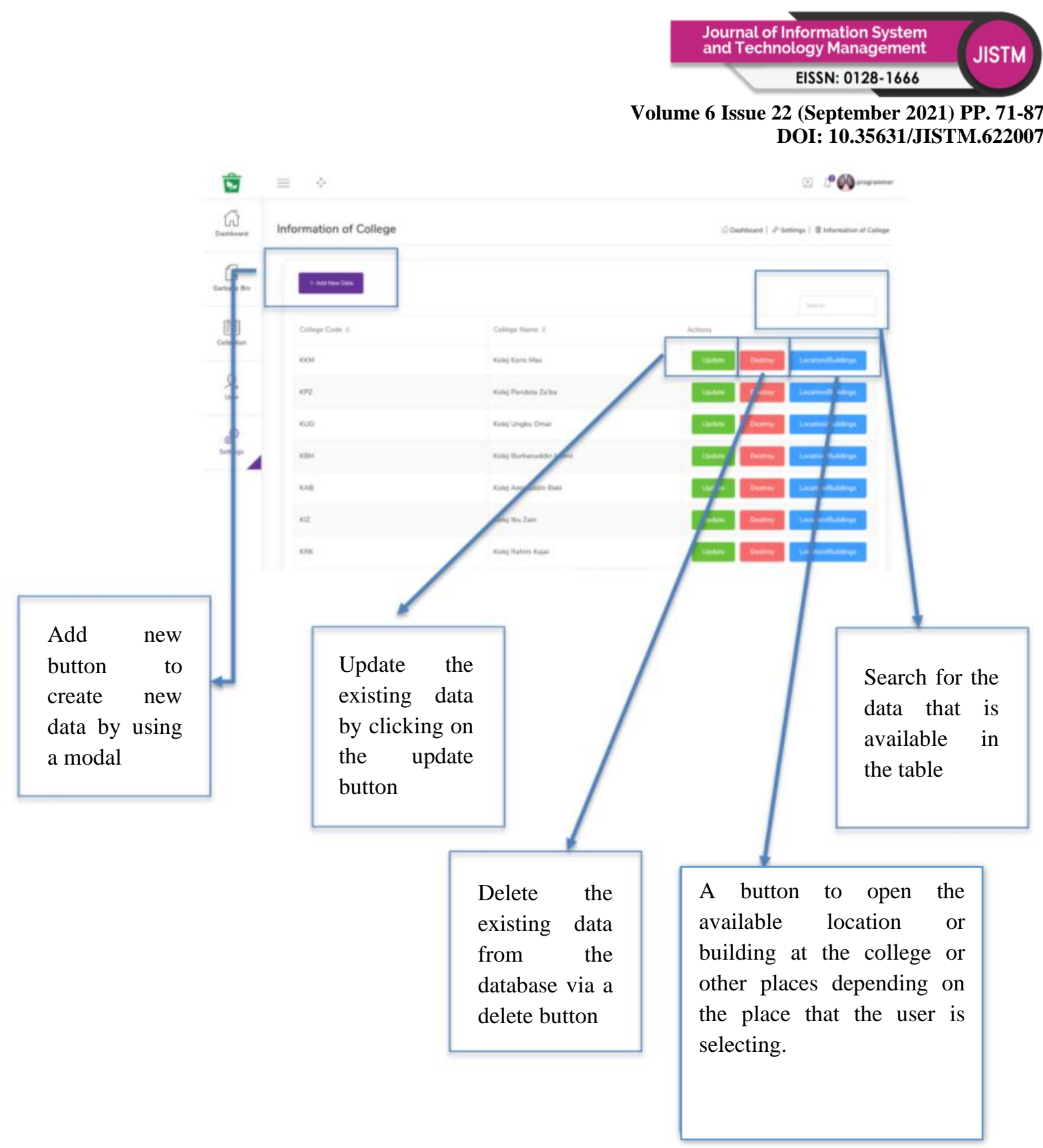

Figure 10: Location Maintenance 


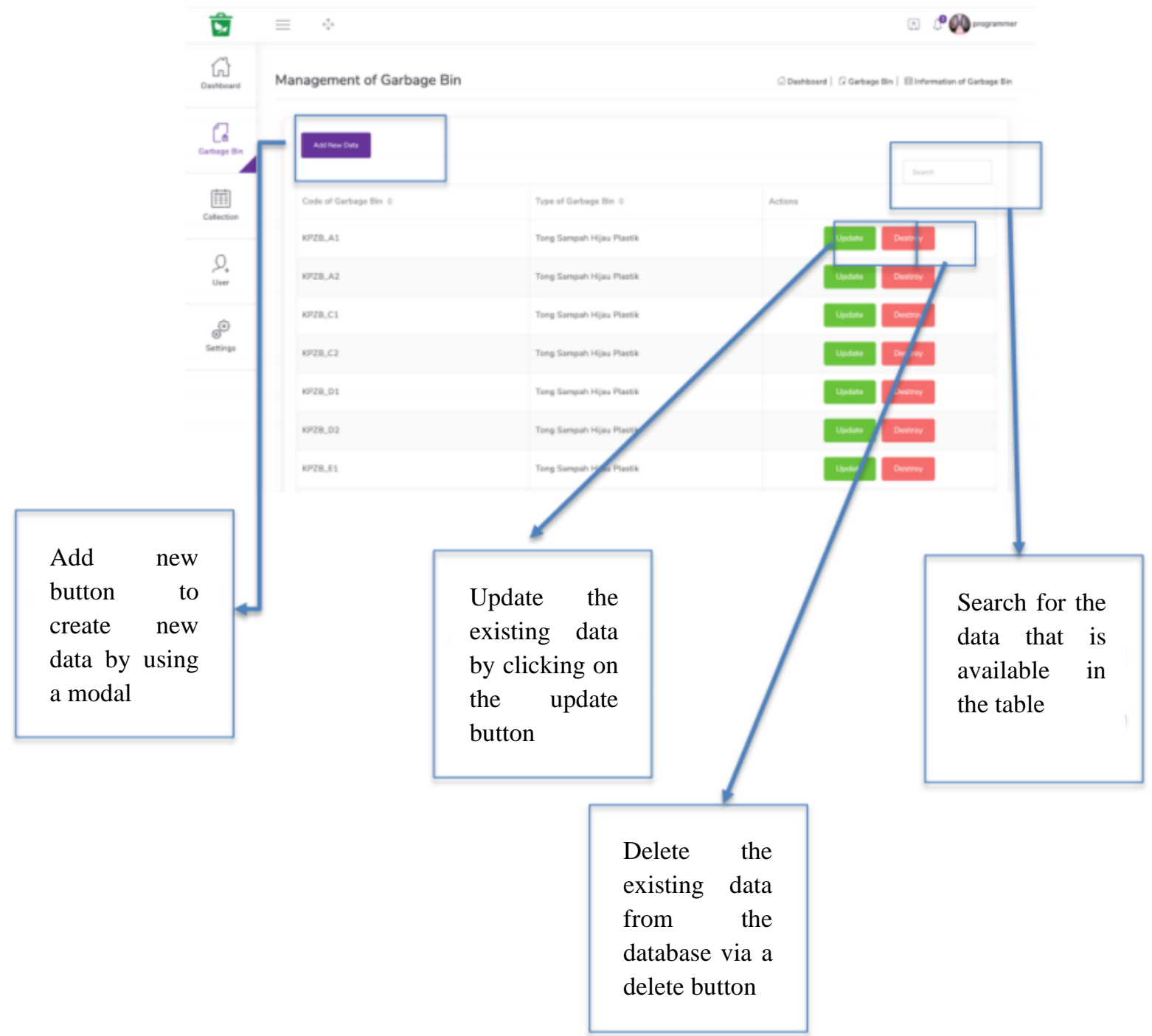

Figure 11: Garbage Bin Maintenance 


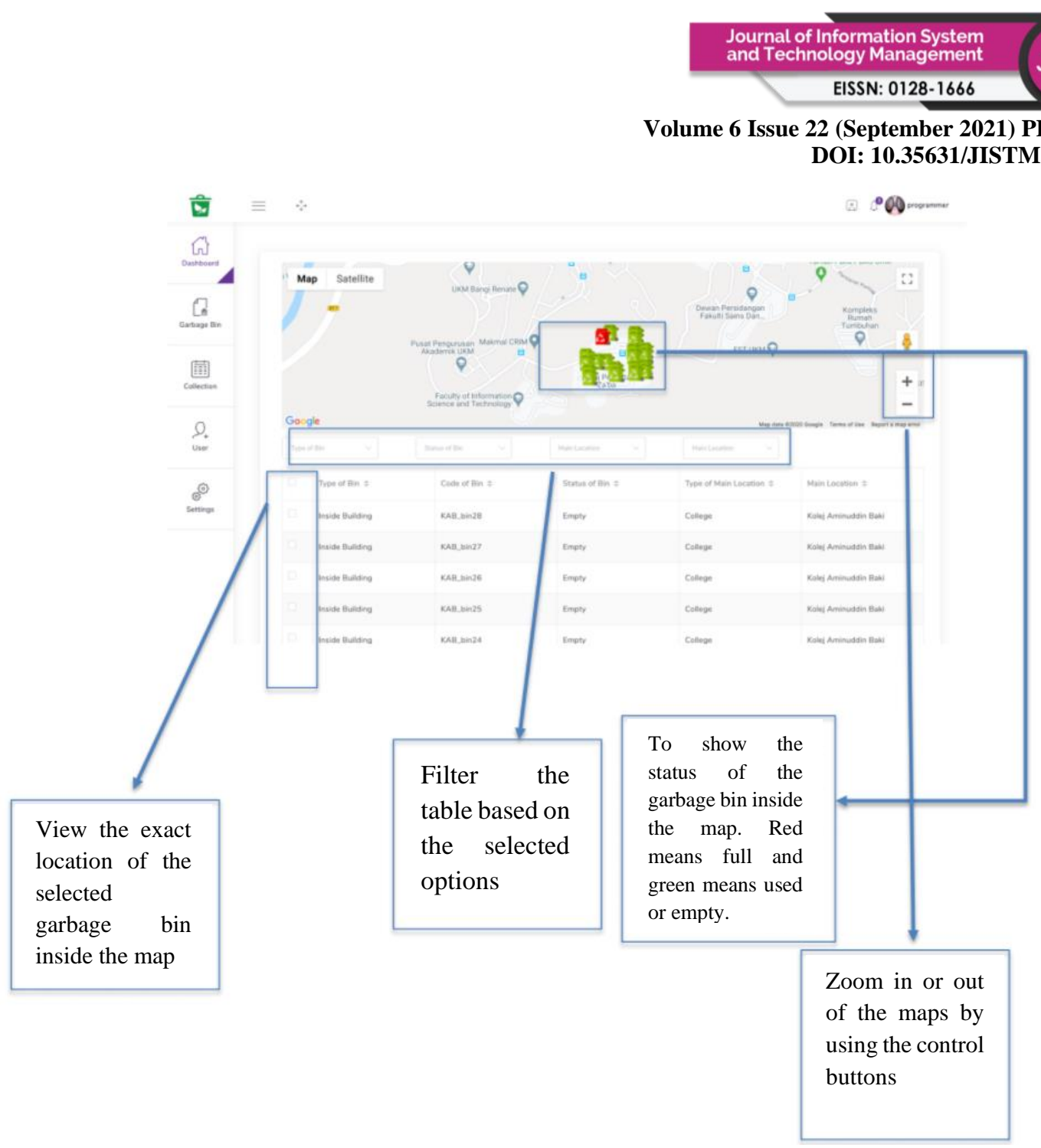

Figure 12: Garbage Bin Location (Display in Maps Form)

\section{Discussion}

Malaysia has the aspiration to establish sustainable management of solid waste (Ghulam Khan et al., 2019). However, some factors make it a challenge since it is a costly operation as it takes up many resources and labour (Teoh et al., 2020). Act 672 allocates the rules regarding solid waste management (Ghulam Khan et al., 2019; Razali et al., 2019). As far as sustainable landfilling practices are concerned, other issues related to economic limitations such as lack of financial support and increased land price are among Malaysia's issues in this context (Ghulam Khan et al., 2019). The insufficient financial support from the government has resulted in a monopoly by certain providers on waste management, treatment and disposal services (Ghulam Khan et al., 2019).

On the university campus, the elected contractor is the one who oversees the handling of waste services. For example, Universiti Kebangsaan Malaysia (UKM) has signed a Memorandum of Agreement (MoA) with Alam Flora Sdn. Bhd. on 18 December 2008 as an establishment to apply an Integrated Solid Waste Management program at UKM (Tiew et al., 2010; Tiew et al., 2011). The MoA opens ways for the university to achieve its mission of a Zero-Waste campus and be a role model for other universities in Malaysia (Tiew et al., 2010; Tiew et al., 2011). However, some providers may provide poor waste management, which results in harmful effects brought to everyone in the universities. The university management may not be aware 
of the issue since no time or person in charge handles everything related to waste management. Therefore, the existence of the proposed solution is to ensure proper waste management in the university campus. The university management can monitor the solid waste management process in the university campus to ensure that the solid waste management complies with their Standard Operating Procedures (SOP) in this context. Besides that, everyone on the university campus can also be aware of the SOP of proper waste management.

Not everyone is aware of how to handle solid waste properly in terms of management. Razali et al. (2019) lists down the government agencies related to solid waste management: the Ministry of Urban Wellbeing, Housing and Local Government (KPKT), National Solid Waste Management Department, or Jabatan Pengurusan Sisa Pepejal Negara (JPSPN), and SWCorp. These departments are not working in isolation but are working together in making the overall legislation on waste management regardless of the state or region, and local authorities are tasked to implement the same at grass root levels (Jereme et al., 2015). The Federal, State, and Local Authorities play significant roles in the waste management stream in Malaysia (Jereme et al., 2015). Therefore, they need to work together to educate the public as well.

\section{Future Work}

Creating an actual prototype of the smart bin and the web user module has made it possible to produce a SWMS by integrating them well with cloud services. With the advancement of existing and future technologies such as cloud service, Artificial Intelligence (AI), IoT, and $5 \mathrm{G}$, the advancement of the SWMS to a better system is foreseeable. The following shows some focus on the foreseeable future:

- Integrate the existing modules with cloud services and develop a mobile application for the users.

- Develop features such as route navigation in terms of its algorithm and feature recognition by using AI technologies.

- Implement the navigation functionality inside the mobile and the web user applications for a more effortless viewing experience.

- Deploy the system to more facilities to further enhance the user application's usability and obtain feedback to improve the system.

The enhancement and routing function will also be helpful in calculating the best path in the collection routes, seeking efficiency with a lower cost of operating a fleet of trucks (Ahmad et al., 2018).

\section{Conclusion}

The population will continue to increase in the future, resulting in more work required to manage solid waste more effectively and efficiently. The increase in public awareness is required to understand the importance of preserving the environment by having a good manner in managing waste. In this regard, we see an increase in the study and discussion of smart city design worldwide to solve this problem. This article has presented an efficient IoT and cloudbased SWMS to improve towards a comfortable and sustainable environment with this approach. The usage of sensor and communication technologies also helps to ensure that the system can run effectively. Additionally, the enhancements as in the future work, will also improve the system to the next level. 


\section{Acknowledgement}

This research work has been funded by Enhancement Strategies for Zero Waste Campus [LRGS MRUN/F2/01/2019] and Smart Garbage Bin with IoT Applications [LRGS MRUN/F2/01/2019/1/2].

\section{References}

A. A., M., Vikas, K., Saurbah, S., \& T. Shah, P. (2020). Smart Solid Waste Management System Using IOT. International Journal of Future Generation Communication and Networking, 13(3s), 396-405.

Ab Majid, N. A., Ismail, N. A., \& Hassan, S. (2019). IoT-Based Smart Solid Waste Management System A Systematic Literature Review. International Journal of Innovative Technology and Exploring Engineering (IJITEE), 8(8), 1456-1462.

Ahmad, M., Badr, K.B., Salwana, E., Zakaria, N., Tahar, Z., \& Sattar, A. (2018). An Ontology for the Waste Management Domain. Twenty-Second Pacific Asia Conference on Information Systems.

Alaloul, W. S., Liew, M. S., Zawawi, N. A. W. A., \& Mohammed, B. S. (2018). Industry Revolution IR 4.0: Future Opportunities and Challenges in Construction Industry. MATEC Web of Conferences, 203, 1-7.

Amasuomo, E., \& Baird, J. (2016). The Concept of Waste and Waste Management. Journal of Management and Sustainability, 6(4), 88.

Basu, R. (2009). Solid Waste Management-A Model Study. Sies Journal of Management, 6, $20-24$.

Beranek, W. (1992). Solid Waste Management and Economic Development. Economic Development Review, 10, 49.

da Cruz, M. A. A., Rodrigues, J. J. P. C., Al-Muhtadi, J., Korotaev, V. V., \& de Albuquerque, V. H. C. (2018a). A Reference Model for Internet of Things Middleware. IEEE Internet of Things Journal, 5(2), 871-883.

da Cruz, M. A., Rodrigues, J. J., Sangaiah, A. K., Al-Muhtadi, J., \& Korotaev, V. (2018b). Performance evaluation of IoT middleware. Journal of Network and Computer Applications, 109, 53-65.

Demirbas, A. (2011). Waste management, waste resource facilities and waste conversion processes. Energy Conversion \& Management, 52(2), 1280-1287.

Dijkema, G. P. J., Reuter, M. A., \& Verhoef, E. V. (2000). A new paradigm for waste management. Waste Management, 20(8), 633-638.

Fong, C. M. (2019). Generating more waste than ever. Retrieved 23 April 2021, from https://www.thestar.com.my/news/nation/2019/07/30/generating-more-waste-thanever

Ghiani, G., Laganà, D., Manni, E., Musmanno, R., \& Vigo, D. (2014). Operations research in solid waste management: A survey of strategic and tactical issues. Computers \& Operations Research, 44(4), 22-32.

Ghulam Khan, I. N. \& Dahalan, W. S. A. W. \& Nopiah, Z. (2019). A Survey on Perceptions of Legal and Non-Legal Factors Affecting Sustainable Solid Waste Management in Malaysia. Akademika, 89, 41-51.

Harith, M. Z. M. Z., Hossain, M. A., Ahmedy, I., Idris, M. Y. I., Soon, T. K., \& Noor, R. M. (2020). Prototype Development of IoT Based Smart Waste Management System for Smart City. IOP Conference Series: Materials Science and Engineering, 884, 1-7. 
Harith, M. Z. M. Z., Hossain, M. A., Ahmedy, I., Idris, M. Y. I., Soon, T. K., \& Noor, R. M. (2020). Prototype Development of IoT Based Smart Waste Management System for Smart City. IOP Conference Series: Materials Science and Engineering, 884, 1-7.

Jereme, I. A., Chamhuri, S., Begum, R. A., Abdul Talib, B. \& Alam, M. M. (2015). Assessing Problems And Prospects of Solid Waste Management in Malaysia. e-Bangi, 10, 70-87.

Kanase, R.A., \& Kanse, Y. (2018). A Review Paper on IoT Based Smart Garbage Alert System. International Journal of Science and Research (IJSR), 7(5), 1810-1813.

Leblanc, R. (2020). An Introduction to Solid Waste Management. Retrieved 23 April 2021, from https://www.thebalancesmb.com/an-introduction-to-solid-waste-management2878102

Mohd Yusof, N., Jidin, A. Z., \& Rahim, M. I. (2017). Smart Garbage Monitoring System for Waste Management. MATEC Web of Conferences, 97, 1-5.

Nadi, B., Ahmad, R., Pirasteh, S., Shamshiry, E. \& Mokhtar, M. (2011). Challenges of Solid Waste Management in Malaysia. Research Journal of Chemistry and Environment. 15.

Omran, A., Mahmood, A., \& Aziz, H. A. (2007). Current Practice of Solid Waste Management in Malaysia and its Disposal. Environmental Engineering and Management Journal, 6(4), 295-300.

Pardini, K., Rodrigues, J. J., Diallo, O., Das, A. K., de Albuquerque, V. H. C., \& Kozlov, S. A. (2020). A Smart Waste Management Solution Geared towards Citizens. Sensors, 20(8), $1-15$.

Razali, F., Choong, W. W., \& Daud, D. (2019). A Review of Malaysia Solid Waste Management Policies to Improve Recycling Practice and Waste Separation among Households. International Journal of Built Environment and Sustainability, 6(1-2), 3945.

Smartbin Waste Management. (2019, 18 December). Retrieved 27 April 2021, from http://mpk.terengganu.gov.my/en/node/923

Tchobanoglous, G., Theisen, H., \& Vigil, S. (1993). Integrated Solid Waste Management: Engineering Principles and Management Issues. Water Science \& Technology Library, 8(1), 63-90.

Teoh, J. S., Islam, M. S., Misran, N., Baharuddin, M. H., Arshad, H., Islam, M. R., . . Islam, M. T. (2020). An Internet of Things Based Smart Waste Management System Using LoRa and Tensorflow Deep Learning Model. IEEE Access, 8, 148793-148811.

Tiew, K. G., Kruppa, S., Ahmad Basri, N. E. \& Basri, H. (2010). Municipal Solid Waste Composition Study at Universiti Kebangsaan Malaysia Campus. Australian Journal of Basic and Applied Sciences, 4(12), 6380-6389.

Tiew, K. G., Watanabe, K., Ahmad Basri, N. E., Md. Zain, S. \& Basri, H. (2011). Reducing Waste Disposal from Universiti Kebangsaan Malaysia Campus By 2-Bins Recycling System. Journal of Civil Engineering, Science and Technology, 2, 31-35.

Vergara, S. E., \& Tchobanoglous, G. (2012). Municipal Solid Waste and the Environment: A Global Perspective. Environment and Resources, 37(37), 277-309.

White, P. R., Franke, M., \& Hindle, P. (1995). Integrated Solid Waste Management: A Lifecycle Inventory. Berlin: Springer.

Zeb, A., Ali, Q., Saleem, M. Q., Awan, K. M., Alowayr, A. S., Uddin, J., . . Bashir, F. (2019). A Proposed IoT-Enabled Smart Waste Bin Management System and Efficient Route Selection. Journal of Computer Networks and Communications, 2019, 1-9. 
Volume 6 Issue 22 (September 2021) PP. 71-87 DOI: 10.35631/JISTM.622007

Zulkipli, F., Nopiah, Z. \& Basri, N. \& Cheng, J. (2018). Dynamical Integrated Framework Development of Solid Waste Management in Malaysia. International Journal of Engineering and Technology. 7(4.33), 21-24. 